\title{
DEBATE
}

\section{Response to Kuhse}

\section{R M Perkin, D B Resnik}

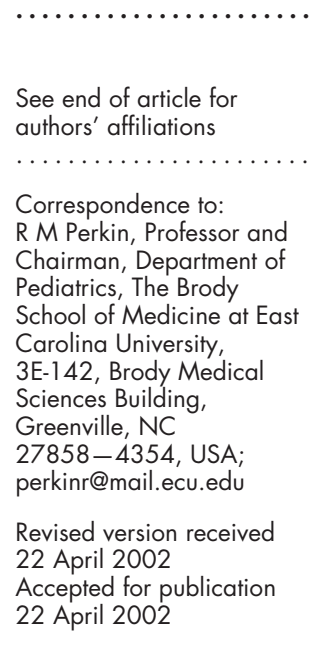

....................

J Med Ethics 2002;28:273-274

In this short paper, we respond to critics of our original paper, The agony of agonal respiration: is the last gasp necessary?. A common thread in both Hawryluck's and Kuhse's responses is the difficulties encountered when using the agent's intentions to make moral distinctions between using neuromuscular blocking drugs to palliate versus using neuromuscular blocking drugs to kill. Although this difficulty does exist we maintain that the intentions of the physician must matter when providing end-of-life care.
$\mathrm{K}$ uhse criticises our application of the doctrine of double effect to the problem of agonal respiration. ${ }^{1}$ She points encounter a problem with describing the act question - that is, the administration of muscle relaxants during agonal respiration. We could describe the act in any number of ways, some of which would imply that it is an act of killing. She is correct to point out that killing is not a basic action and we must appeal to the agent's intentions to determine whether the act in question is killing or something else. But this same problem occurs when we are talking about other actions, such as taking a patient off a respirator or not resuscitating a patient. In some cases, these actions would constitute killing by an act of commission or an act of omission. We justify these actions by appealing to the intentions of the actors. We can infer a person's intentions from his or her circumstances, behaviour, and communications. If a physician weans a terminally ill patient from a respirator, we do not call this action "killing" because we infer that the physician's intention is to reduce the patient's suffering, not to kill the patient. We can make the same sort of inference in the agonal respiration case; we infer that the physician's intention is to relieve suffering not to kill the patient. Obviously, intentions are subjective and therefore epistemologically problematichow can we ever know what anyone intends to do? On the other hand, end-of-life decision making and ethics would make no sense at all if we did not assume that we can ascribe intentions to physicians, patients, family members, and other health care professionals. One does not need to subscribe to the doctrine of double effect in order to grasp this basic point. Even the well accepted practices of withholding and withdrawing care cannot be morally justified without ascribing humane intentions to the actors. So, we admit that one needs a theory of human intentions in order to apply the doctrine of double effect to the problem of agonal respiration, but this is not a fatal flaw in our approach, since one needs a theory of human intentions to make sense of virtually all medical decisions at the end of life in any case.

Kuhse argues that it might sometimes be morally justifiable to administer muscle relaxants to patients in agonal respiration, even if we do not rely on the principle of double effect. She says that administering muscle relaxants in such a case may benefit the patient (by relieving suffering) or benefit the patient's family. But how can she maintain this view without addressing problems having to do with the intentionality of the act? If you administer muscle relaxants, your action could be construed as killing, and most people regard killing as immoral and illegal. It seems to us that you can respond to this charge in two ways. First, you can defend the act by describing it as something other than killing - that is, as relieving suffering. This is the option we prefer. Second, you could admit that the act is indeed killing but maintain that it is justifiable killing. We would prefer to avoid construing the action as killing, since this would make it a type of euthanasia and murder. Of course, one could maintain that physicians should do nothing to stop agonal respiration. They could stand by the bedside until their dying patients take their last gasp. We see no reason why patients or their families should be required to bear this burden once the patient has chosen to withdraw respiratory support and death is imminent.

Hawryluck makes a very important point when she asks whether neuromuscular blockers might actually make the patient's suffering worse, if the patient is conscious, unable to breathe, and aware of his or her inability to breathe. ${ }^{2}$ This is a valid point. We do not know what the gasping patient may be experiencing. Given this uncertainty, we should take steps to reduce the patient's suffering.

We are advocating the use of muscle relaxants in a very small and specific group of patients. They are easy to recognise: they are terminal, have been well sedated, are unresponsive, and have entered a prolonged gasping phase. If these patients can suffer, the likely cause of suffering would be the intense muscle contraction of the prolonged gasps.

Hawryluck also points out difficulties with using the agent's intentions to make moral distinctions between using neuromuscular blockers to palliate $\mathrm{v}$ using neuromuscular blockers to kill. We have discussed this issue in our paper and in our response to Kuhse. We admit that the distinction between "intending death" and "intending palliation (and foreseeing death)" can be murky and ambiguous in end-of-life decision making. Nevertheless, intentions (and wants, desires, and motives) do matter, and we must do our best to understand 
these subjective states of mind. In ethics, one's mental state can make the difference between euthanasia/murder and palliation.

Finally, Hawryluck asks if our families were prepared for what was going to happen. In both of our case examples, the families received a very clear description of what the end of life would look like. The relationship was so honest that when they asked if "there was anything else we could give their children to stop the gasping" we answered "yes, but we cannot use that category of drugs". Both families pleaded that we use the neuromuscular blocking drugs; we did not, but rather continued to escalate our already high level of sedation. One of us (RMP) is haunted by the memory of the syringe of medicine being given, which he knew would not effectively end the gasping. These families are not comforted by the fact that we acted in an "ethically permissible" manner.

\section{Authors' affiliations}

R M Perkin, Department of Pediatrics, The Brody School of Medicine at East Carolina University, Greenville, North Carolina, USA

D B Resnik, Department of Medical Humanities and The Bioethics Center, The Brody School of Medicine at East Carolina University, Greenville, North Carolina, USA

\section{REFERENCES}

1 Kuhse H. Response to Ronald M Perkin and David B Resnik. The agony of trying to match sanctity of life and patient-centred medical care. Journal of Medical Ethics 2002;28:272-4.

2 Hawryluck L. Neuromuscular blockers-a means of palliation? Journal of Medical Ethics 2002;28:170-2.

\section{COMMENTARY}

After agreeing that the doctrine of double effect (DDE) cannot settle the question of how actions ought to be described, Perkin and Resnik suggest that this is not an insurmountable problem since "we justify these actions by appealing to the intentions of the agents".

This response misses the point. It rests on a confusion between the permissibility and the justifiability of actions. Under condition (1) of the DDE, an action is permissible if "the goal of the action is itself good". Hence, if I describe my action of administering a lethal drug as "relieving suffering", rather than "killing", it is in principle permissible. Whether a permissible action is also justified is determined by condition (4), which states that there must be a proportionately good reason. Under the DDE, it would, other things being equal, be permissible to cause the death of a patient, to relieve her (temporary) suffering, but the action might well be unjustified under condition (4). On the other hand, bringing about the death of a terminally ill and suffering patient might be justifiable under condition (4), but would be impermissible if the agent were (to admit that she was) "directly intending" the patient's death. In short, the justifiability of actions is one thing, their permissibility is quite another.

This conclusion underlines my earlier point. Because the DDE cannot set limits to the description of actions, it will sometimes allow caring physicians to rig the descriptions of end-of-life decisions they believe to be justified in such a way as to make them also permissible.

Perkin and Resnik claim that ethics in general and end-oflife decision making in particular presuppose that we can ascribe intentions to agents. This claim is either ambiguous, or false. Intentional actions presuppose deliberate and voluntary choice. This is not the same as claiming that there is a morally relevant distinction between what agents directly intend and what they merely foresee. Ethics presupposes the former, but many philosophers, ethicists, and lawyers deny the latter, holding that moral agents are responsible for all the foreseen consequences of their actions.

While rejecting the DDE, I have suggested that it might sometimes be morally justifiable to bring about the death of a patient by administering muscle relaxants. Contrary to Perkin and Resnik, this does not presuppose a distinction between intention and foresight. One might, for example, describe any medical end-of-life decision (regardless of whether it involves the administration of a lethal drug, or the foregoing of life-sustaining treatment) as a wrongful killing if it were to lack the consent of a competent patient, or if it is, say, contrary to an incompetent patient's best interests. If, on the other hand, a dying competent patient seeks help from a doctor to end her life, we might agree to describe this action not as "killing" but as "helping to die".

Traditional morality and the law prohibit killing. In light of this, Perkin and Resnik state that they prefer to describe the administration of muscle relaxants not as justifiable killing, but as "as something other than killing-that is, as relieving suffering". As a pragmatic response this is perhaps understandable. But it comes at a price; it rests not only on the deeply flawed doctrine of double effect, but also on some dubious thinking surrounding the notion of intentional action and the distinction between the moral permissibility and justifiability of actions.

H Kuhse
Centre for Human Bioethics,
Monash University, Clayton, Victoria 3168, Australia

